University of Wollongong

Research Online

1996

Ross River virus infection on the North Coast of New South Wales

Victoria J. Westley-Wise

University of Wollongong, victoria@uow.edu.au

John Beard

Northern Rivers Area Health Service

Tim Sladden

Northern Rivers Area Health Service

Therese Dunn

Northern Rivers Area Health Service

John Simpson

Northern Rivers Area Health Service

Follow this and additional works at: https://ro.uow.edu.au/ahsri

Research Online is the open access institutional repository for the University of Wollongong. For further information contact the UOW Library: research-pubs@uow.edu.au 


\title{
Ross River virus infection on the North Coast of New South Wales
}

\begin{abstract}
A retrospective follow-up survey was undertaken of residents of the North Coast of New South Wales infected with Ross River virus in 1992. The aims of the study were to describe the epidemiology and acute symptomatology of Ross River virus infection, its natural history during the first 12 months of infection, and its effects on those infected. Questionnaires were distributed to both cases and their medical practitioners. Of 129 people infected, aged between six and 85 years, 81 (63 per cent) were male and 48 (37 per cent) were female. The peak age-specific incidence was in the age group 50 to 59 years. The most common symptoms were arthralgia (95 per cent) and tiredness (91 per cent). Over 60 per cent took time off work. At 12 months follow-up, over 50 per cent reported persistent arthralgia, 35 per cent reported persistent tiredness and 15 per cent were still unable to carry out their normal activities. The median duration of symptoms was in the range 7 to 12 months, and of incapacity was in the range five weeks to three months. There were some differences from previous reports of Ross River virus outbreaks, in the incidence of major symptoms and the duration of illness and incapacity. These are likely to be at least pardy due to inconsistent measurement methods. In this study, there were systematic differences between medical practitioners' and patients' estimates of periods of incapacity. Previous estimates of the direct economic costs and indirect human costs of infection based on data obtained from medical practitioners, although alarming, are almost certainly underestimates.
\end{abstract}

\section{Keywords}

ross, river, virus, infection, north, coast, wales, south

\section{Publication Details}

V. J. Westley-Wise, J. R. Beard, T. J. Sladden, T. M. Dunn \& J. Simpson, "Ross River virus infection on the North Coast of New South Wales", Australian and New Zealand Journal of Public Health 201 (1996) 87-92. 


\title{
Ross River virus infection on the North Coast of New South Wales
}

\author{
Victoria J. Westley-Wise, John R. Beard, Timothy J. Sladden, Thérèse M. Dunn \\ and John Simpson \\ North Coast Public Health Unit, Lismore
}

\begin{abstract}
A retrospective follow-up survey was undertaken of residents of the North Coast of New South Wales infected with Ross River virus in 1992. The aims of the study were to describe the epidemiology and acute symptomatology of Ross River virus infection, its natural history during the first 12 months of infection, and its effects on those infected. Questionnaires were distributed to both cases and their medical practitioners. Of 129 people infected, aged between six and 85 years, 81 (63 per cent) were male and 48 (37 per cent) were female. The peak age-specific incidence was in the age group 50 to 59 years. The most common symptoms were arthralgia (95 per cent) and tiredness (91 per cent). Over 60 per cent took time off work. At 12 months follow-up, over 50 per cent reported persistent arthralgia, 35 per cent reported persistent tiredness and 15 per cent were still unable to carry out their normal activities. The median duration of symptoms was in the range 7 to 12 months, and of incapacity was in the range five weeks to three months. There were some differences from previous reports of Ross River virus outbreaks, in the incidence of major symptoms and the duration of illness and incapacity. These are likely to be at least partly due to inconsistent measurement methods. In this study, there were systematic differences between medical practitioners' and patients' estimates of periods of incapacity. Previous estimates of the direct economic costs and indirect human costs of infection based on data obtained from medical practitioners, although alarming, are almost certainly underestimates. (Aust N Z J Public Health 1995; 19: 87-92)
\end{abstract}

$\mathbf{R}$ OSS RIVER virus infection is the most prevalent vector-borne disease in Australia, ${ }^{1}$ occurring across the continent. ${ }^{2}$ In southeastern Australia, epidemics occurred in 1928, 1942, 1945, 1956, 1971, 1974 and $1983-84 .{ }^{3}$ Within New South Wales (NSW) the largest and most widespread documented outbreaks in recent decades have been concentrated in the inland areas of the southwest of the state. For example, in 1956 an estimated 1000-2000 cases occurred in Mildura alone. ${ }^{4}$ In 1983-84, 1196 laboratory-confirmed cases were diagnosed throughout NSW, predominantly in the catchment areas of the Murray and Darling Rivers. ${ }^{4}$ The estimated cost of the 1983-84 outbreak was $\$ 10$ million. $^{3}$

Ross River virus has also been shown to be active on the South, Central and North Coasts of NSW. ${ }^{5-8}$ Although the highest alphavirus (mainly Ross River) antibody prevalence rates along the NSW coastal strip have been documented on the North Coast (about 16 per cent), ${ }^{8}$ it was observed as recently as 1985 that few clinical cases of the virus apparently occurred in this area. ${ }^{9}$ However, more recently, infectious diseases notification data for NSW have shown that, at least in some years, a large proportion of NSW cases are in North Coast residents. For example, published preliminary surveillance data showed that over one-third of cases in NSW occurred among North Coast residents in 1990 (96

Correspondence to Dr V. J. Westley-Wise, Director, Illawarra Public Health Unit, PO Box 66, Keiraville, NSW 2500. Fax (042) 264917. of 285,34 per cent $)^{10}$ and again in 1992 (112 of 299, 38 per cent). ${ }^{11}$

Although the first national profile of Ross River virus, in 1981-82, documented a remarkable consistency in clinical presentation of the disease across Australia, ${ }^{2}$ epidemics apparently differ in clinical severity. The few studies that have attempted to quantify the level and duration of incapacity have led to variable conclusions. It has been postulated that these differences may be due to different virulence of strains. ${ }^{9,12}$ However, it is unclear to what extent these differences are an artefact of the variable criteria and methods of measurement used in the investigations. ${ }^{12}$

This investigation was a retrospective follow-up survey of cases of Ross River virus, diagnosed in 1992, in people who were resident on the North Coast of NSW. The aims of the investigation were to describe the epidemiology and acute symptomatology of the disease, its natural history during the first 12 months, and its effects in terms of time off work and persistent incapacity. Methods were similar to those used to investigate an outbreak of the virus in Western Australia (WA) in $1988-89,{ }^{12}$ permitting comparisons between a large outbreak and this smaller outbreak in coastal NSW in 1992.

\section{Methods \\ Case definition and source of surveillance data}

In NSW, arboviral infections are notifiable by laboratories, under the Public Health Act 1991, on serological or microbiological confirmation, defined as a 
fourfold or greater rise in antibody titres between the acute and convalescent phase serum specimens obtained at least two weeks apart; the demonstration of specific IgM antibodies; or isolation of arbovirus from the blood. ${ }^{13}$

The NSW Infectious Diseases Surveillance System notification database was used to describe the demographic features of all North Coast residents who were diagnosed with Ross River virus during 1992.

\section{Questionnaire surveys}

From January 1992, the medical practitioners for all notified cases were mailed questionnaires about one to two months after the date of notification. These inquired about the date of onset of their patients' illnesses and the periods of their incapacity (defined as inability to work or perform daily duties).

From the end of July 1993, all notified cases (or the parents of cases aged under 15 years) diagnosed within the seven-month period from 1 January 1992 to 31 July 1992 (constituting all but nine notifications in 1992) were given questionnaires. These questionnaires inquired about symptoms and incapacity associated with their illness, up to a minimum of 12 months after onset, and the use of pharmaceutical and other treatments. It was adapted from the questionnaire developed to investigate the outbreak of Ross River virus in southwestern WA in $1988-89 . .^{12}$

\section{Data analysis}

Data from these questionnaires and from routine notifications were analysed using the Epi Info software program. ${ }^{14}$ Statistical differences between subgroups for categorical variables were tested by the chi-square statistic, and for continuous variables, the Kruskal-Wallis test was used. Resident population estimates from the Australian Bureau of Statistics were used to calculate crude annual incidence rates of Ross River virus infection for the North Coast and its local government areas. ${ }^{15}$

\section{Results}

A total of 94 completed questionnaires was received from medical practitioners, and 80 from patients, representing response rates of 73 per cent and 67 per cent respectively. The age, sex and geographical distributions of cases for which medical practitioners responded, and of patients who responded, were similar to the distributions for the total population of notified cases in 1992.

\section{Demographic features}

Of the 129 residents of the North Coast who were diagnosed in 1992, 81 (63 per cent) were males and 48 (37 per cent) were females, a ratio of $1.7: 1$. The incidence rate for females was 26 , and for males was 42 , per 100000 population.

The ages ranged from six to 85 years, with a mean age of 42.5 years (standard deviation (SD) 13.4 years). About 77 per cent of cases (99) were in those aged between 30 and 59 years. No cases were in females aged 60 years or over. The peak age-specific incidence for both males and females was in the age rate per 100000

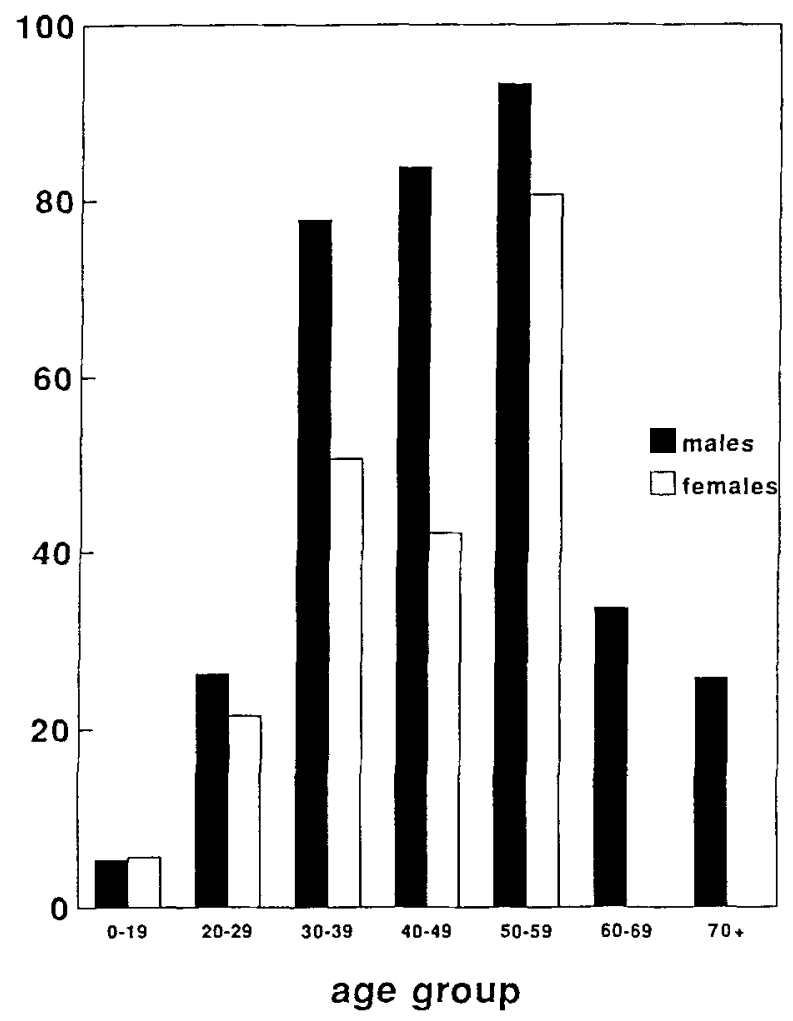

Figure 1: Age- and sex-specific incidence of Ross River virus notifications, North Coast, NSW, $1992(n=128)$

group 50-59 years, rates being 80.7 and 93.3 per 100000 respectively (Figure 1 ).

Cases diagnosed in 1992 were mainly in those resident on the far North Coast, between the Tweed and Clarence Rivers. Although estimates of rates by local government area were based on small numbers, incidence decreased significantly along a north-south gradient (chi-square for trend for the 11 coastal areas $=17.0, P<0.0001)$.

\section{Onset of illness}

The distribution of cases was clearly seasonal, with 67 people (64 per cent) becoming ill in the threemonth period from January to March (Figure 2). The median estimated delay between onset of symptoms and laboratory diagnosis was 24 days. Seventeen patients (16 per cent) were diagnosed during the first week of illness, 62 (59 per cent) during the first four weeks and 88 ( 84 per cent) within the first three months of illness. For six patients $(6$ per cent), the reported onset of illness was more than 12 months before the date of laboratory diagnosis.

\section{Symptoms}

Arthralgia was the most common symptom (Table 1). The triad of arthralgia, stiffness and swelling (as a proxy measure of arthritis) was reported by less than half ( 47 per cent). The joints most commonly affected (by arthralgia, stiffness and/or swelling) were the knees and ankles (each reported to be affected by 64 per cent), followed by the fingers ( 63 
number of cases

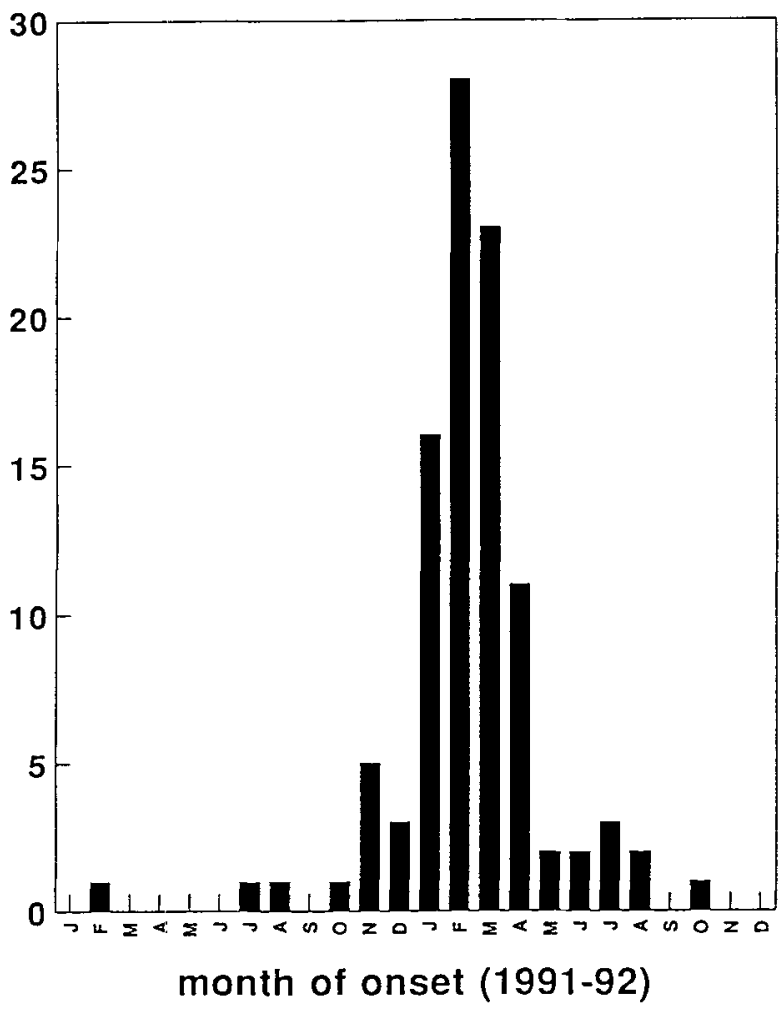

Figure 2: Rosis River virus notifications by dates of onset, North Coast, NSW, $1992(n=124)$. Five cases reported dates of onset before 1991: June 1983, March 1985, January 1989, June 1990, June 1990.

per cent) and the wrists (61 per cent). Other common acute symptoms were tiredness (91 per cent), joint stiffness ( 79 per cent), lethargy ( 78 per cent) and myalgia (63 per cent). Fever was reported by only 60 per cent and skin rash by only 40 per cent of cases.

\section{Duration of illness and incapacity}

Of the 76 people for whom relevant information is available, only five ( 7 per cent) reported symptomatic recovery within four weeks and 30 (40 per cent) within six months. Thirty-one (41 per cent) reported that they had not completely recovered within 12 months from the onset of illness. The median self-reported duration of symptoms was in the range 7 to 12 months.

Over half reported arthralgia lasting for 12 months, but only 10 (13 per cent) reported symptoms of arthritis (arthralgia, stiffness and swelling), persisting for at least 12 months. Over one-third reported tiredness persisting for at least 12 months. Other constitutional symptoms, such as fever, headache and influenza-like illness, were generally short-lived. Depression persisting for at least 12 months was reported by 20 per cent of cases.

Those who reported arthralgia persisting for more than six months were significantly older than the other cases $(P=0.010$, Kruskal-Wallis test). Other symptoms tended to persist in those who were older, although these differences were not significant. There were no significant differences in the proportion of males and females reporting symptoms persisting for longer than six months.

Self-reported functional recovery (defined as ability to carry on normal activities) was more rapid than symptomatic recovery. Of the 74 cases for whom relevant information is available, 11 (15 per cent) reported that they had resumed their normal activities within one week, 28 (38 per cent) within four weeks and 57 (77 per cent) within six months. However, eleven (15 per cent) reported that they were still unable to carry out their normal activities at 12 months after the onset of their illness. The median duration of incapacity reported by patients was in the range five weeks to three months.

Those who reported not resuming their normal activities for longer than six months were on average older than the others $(P=0.036$, Kruskal-Wallis test). The proportions of males and females reporting not resuming their normal activities for longer than six months were similar (males: 23 per cent, females: 22 per cent).

Table 2 summarises the self-reported effects on various activities of daily living in the acute phase of the illness and at the time of the survey (median time from onset to follow-up 16.8 months). At the onset of illness, 30 to 35 per cent were unable to walk, dress and undress, or get in and out of bed, unaided. The 9 to 12 per cent who were unable to perform each these functions at six months remained incapacitated at the time of follow-up. While over 70 per cent reported being unable to garden or do sport or exercise at the onset of illness,

Table 1: Number and proportion of cases of Ross River virus, by duration and type of reported symptoms, North Coast of New South Wales, $1992(n=80)$

\begin{tabular}{|c|c|c|c|c|c|c|c|c|}
\hline \multirow[b]{2}{*}{ Symptom } & \multicolumn{2}{|c|}{ At onset or any time } & \multicolumn{2}{|c|}{ For at least 4 weeks } & \multicolumn{2}{|c|}{ For at least 6 months } & \multicolumn{2}{|c|}{ For at least 12 months } \\
\hline & $n$ & $\%$ & $n$ & $\%$ & $n$ & $\%$ & & \\
\hline Arthralgia & 76 & 95.0 & 63 & 78.8 & 46 & 57.5 & 42 & 52.5 \\
\hline Tiredness & 73 & 91.3 & 63 & 78.8 & 38 & 47.5 & 28 & 35.0 \\
\hline Joint stiffness & 63 & 78.8 & 49 & 61.3 & 34 & 42.5 & 31 & 38.8 \\
\hline Lethargy & 62 & 77.5 & 51 & 63.8 & 24 & 30.0 & 21 & 26.3 \\
\hline Myalgia & 50 & 62.5 & 37 & 36.3 & 24 & 30.0 & 22 & 27.5 \\
\hline Fever & 48 & 60.0 & 19 & 23.8 & 8 & 10.0 & 8 & 10.0 \\
\hline Headache & 48 & 60.0 & 26 & 32.5 & 14 & 17.5 & 14 & 17.5 \\
\hline Neck stiffness & 45 & 56.3 & 26 & 32.5 & 15 & 18.8 & 13 & 16.3 \\
\hline Joint swelling & 41 & 51.3 & 28 & 35.0 & 14 & 17.5 & 13 & 16.3 \\
\hline Flu-like illness & 41 & 51.3 & 16 & 20.0 & 7 & 8.75 & 5 & 6.25 \\
\hline Depression & 37 & 46.3 & 26 & 32.5 & 19 & 23.8 & 16 & 20.0 \\
\hline
\end{tabular}


Table 2: Number and proportion of people with Ross River virus unable to perform various daily activities in the acute phases of the illness and at the time of the study, North Coast of New South Wales, $1992(n=77)^{\circ}$

\begin{tabular}{lcccc}
\hline & \multicolumn{2}{c}{ When first ill } & \multicolumn{2}{c}{ At time of study } \\
Activity & $n$ & $\%$ & $n$ & $\%$ \\
\hline Bathe or shower & 17 & 22.1 & 8 & 11.4 \\
Walk unaided & 23 & 29.9 & 7 & 9.1 \\
Dress and undress self & 27 & 35.1 & 7 & 9.1 \\
Get in and out of bed & 27 & 35.1 & 8 & 11.4 \\
Shopping & 42 & 54.5 & 9 & 11.7 \\
Housework & 45 & 58.4 & 10 & 13.0 \\
Social activities & 50 & 64.9 & 10 & 13.0 \\
Gardening & 56 & 72.7 & 11 & 14.3 \\
Sport or exercise & 58 & 75.3 & 13 & 16.9 \\
\hline
\end{tabular}

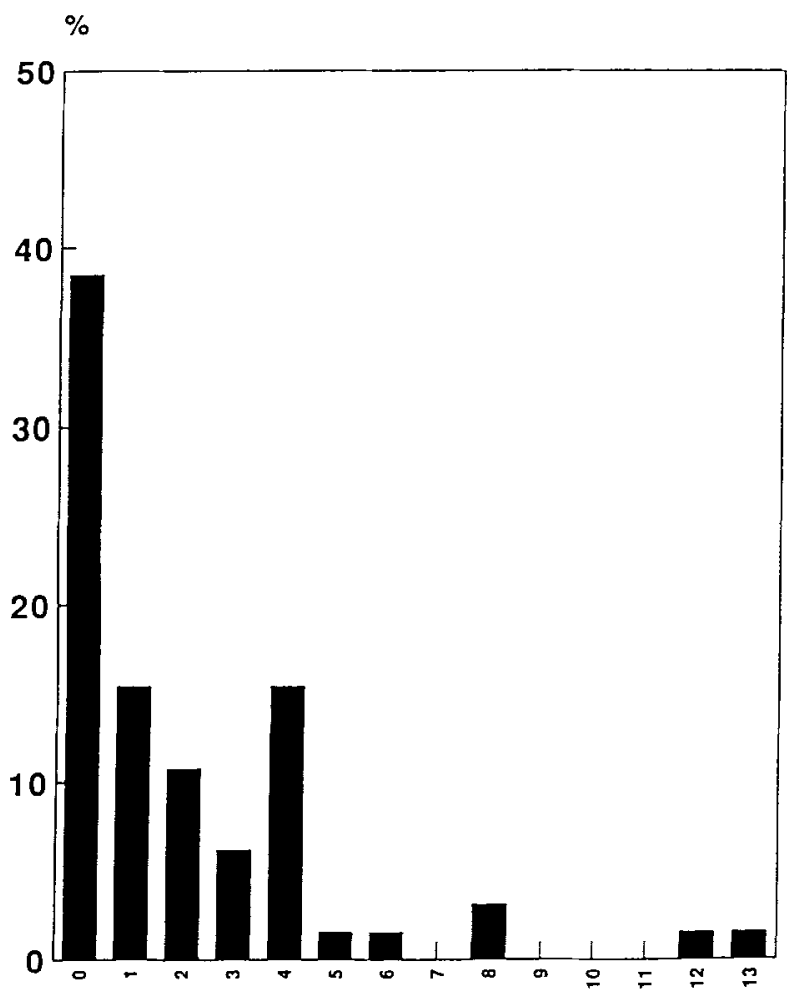

weeks after onset

Figure 3: Week of return to work after Ross River virus infection, North Coast, NSW, $1992(n=65)$. One person had not returned to work at 12 months. $\mathrm{O}=$ no time off work.

only about 15 per cent were still unable to perform these functions at the time of follow-up.

The period of incapacity reported by medical practitioners was shorter than that reported by the patients themselves. Of the subsample of cases $(n=61)$ for whom both doctors and patients responded, the median period of incapacity as reported by medical practitioners was two weeks and as reported by patients was in the range five weeks to three months. Seven of the 12 patients in this subsample who were reported by medical practitioners to have no period of incapacity associated with their illness reported being unable to carry out their normal activities for at least one week, including five patients for five weeks to three months and one patient for 7 to 12 months.

\section{Time off work}

Of the 65 who reported whether any time was taken off work (or home duties), 25 (39 per cent) reported that no time was taken off, although nine of these reported that their normal duties were reduced. Of the 40 (62 per cent) who reported that time was taken off work due to their illness, 10 (25 per cent) reported they had returned to partial or full duties within one week, 31 (78 per cent) within four weeks and 37 (93 per cent) within three months (Figure 3). One person reported that he had not returned to partial or full duties within 12 months, while the remaining two did not respond to this question. The numbers were too small to determine whether time until return to work varied according to occupation.

Four of the 12 patients in the subsample who were reported by medical practitioners to have no period of incapacity associated with their illness reported taking time off work, and a further one of these patients reported no time off but reduced activities.

In addition, eight reported having changed their occupation since the onset of illness (four of whom who attributed this to effects of the infection).

\section{Treatment}

Fifty-four (68 per cent) reported taking medications obtained without a doctor's prescription (over-thecounter), 50 (63 per cent) reported being prescribed medications for their illness, and 33 (41 per cent) reported having other types of treatments, for example, chiropractic, acupuncture, homeopathy and physiotherapy. Paracetamol was the most commonly used medication, as reported by $40(51$ per cent), followed by nonsteroidal anti-inflammatory drugs (42 per cent) and aspirin (25 per cent).

\section{Discussion \\ Demographic features}

The North Coast outbreak followed an early onset of abnormally heavy rainfall in December (1991), which was preceded by an unusually dry period. ${ }^{16}$ Like most previous outbreaks of Ross River virus in Australia, ${ }^{2,4,12,17-19}$ the onset of illness was largely confined to summer and early autumn. The age distribution of cases in 1992 was consistent with previous Australian studies, being uncommon in children, peaking in the age range 25 to 39 years, ${ }^{2,4,17-18}$ and with a mean age in the early $40 \mathrm{~s} .{ }^{12}$ The lower risks in early childhood and the older age groups are thought to be due to a tendency to subclinical infection, ${ }^{20}$ and higher levels of immunity, ${ }^{3}$ respectively. In this study there was a clear male predominance, particularly in the older age groups, which was consistent with the findings of some previous studies, ${ }^{12,21}$ and of seroepidemiological studies, which have shown that antibody prevalence rates tend to be higher in men. ${ }^{8,22}$ That sex differtinces in disease and antibody prevalence rates generally arise after adolescence suggests that the risk of infection is determined by patterns of worl and recreation as well as by geography. ${ }^{22}$ 


\section{Symptoms}

The clinical presentations were broadly consistent with previous reports, the most common symptoms being joint and muscle pains and malaise, followed by constitutional symptoms, such as fever and headache., ${ }^{212}$ The Western Australian (1988-89) study, ${ }^{12}$ which used a similar method to the North Coast study, documented very similar rates of specific acute symptoms, for example, about 95 per cent experienced arthralgia, about 80 per cent lethargy, about 65 per cent myalgia, and about 60 per cent fever. Similarly, the national study of cases in 1981-82 found that about 95 per cent of patients reported arthralgia. ${ }^{2}$

However, comparisons of patterns of symptoms obtained with other, varied, methods are of questionable validity. Firstly, case-ascertainment criteria and definitions of Ross River virus have varied considerably arnong studies. In response to the lack of uniformity in the interpretation and reporting of laboratory results for arboviral infections in Australia, and consequent concerns about the validity of reports, case definitions and reporting criteria have recently been standardised. ${ }^{23}$

Secondly, some previous studies have obtained data from medical practitioners, rather than the patients themselves, which may help explain why the rates of major symptoms reported from this study are considerably higher than some rates previously documented. A report of the 1956 outbreak in South Australia reported that only about a third of patients complained of arthralgia; it was thought that this may have been an underestimate due to patients not volunteering this information to their doctors. ${ }^{21}$ The hypothesis that apparent differences in clinical disease are at least partly due to different methods of measurement is supported by the fact that the national profile of Ross River virus cases in 1981-82 found very similar clinical presentations across the continent. ${ }^{2}$

In addition, in studies with relatively low response rates, selection bias may result when patients are invited to complete questionnaires; for example, more-ill patients may be more likely to respond. In this study, the response rate from patients was only 67 per cent, (compared to 73 per cent from medical practitioners)

The prevalence of rash, however, does appear to vary in different parts of Australia, estimates from previous outbreaks ranging between 40 per cent and 90 per cent. ${ }^{4,12,18,24-26}$ Similarly, the national profile of Ross River virus cases in 1981-82 found that rash was more common in South Australian cases (78 per cent) than in cases generally (40 per cent). It has been postulated that these differences may be due to genetic variants of the virus in different areas. ${ }^{2,12}$

The finding that the main joints involved are the small joints of the wrists, ankles, fingers and knees has been observed previously. 2,4,12,18,24,26 Although other studies have reported similar proportions of patients with arthralgia in each of these joints (that is, about 60 to 70 per cent), ${ }^{2,4}$ these rates were considerably lower than those reported for cases in the 1971 South Australian outbreak ${ }^{18}$ and the 1988-89 WA outbreak. ${ }^{12}$ Nearly all the WA cases, but less than half of the North Coast cases, reported the triad of joint pain, swelling and stiffness. Along with evidence of a more severe acute-phase illness in WA in 1988-89, symptoms in WA patients were also more persistent. ${ }^{12}$ For example, at the time of the WA study (a mean of 36 months after onset), 57 per cent reported arthralgia, 57 per cent tiredness, 35 per cent lethargy and 26 per cent depression, compared to 53 per cent, 35 per cent, 26 per cent and 20 per cent, respectively, for North Coast cases (at 12 months follow-up). This suggests that the clinical severity in North Coast cases in 1992 was considerably less than in the WA outbreak.

\section{Incapacity}

Previous quantitative documentation of symptomatic and functional recovery after Ross River virus infection has been sparse. In common with this study, previous studies have found that only a minority of patients recover within three months, ${ }^{12,27} 50$ to 75 per cent lose time from work (or home duties),, 12 with about 15 per cent of patients being off work for at least a month. ${ }^{12} \mathrm{~A}$ small percentage change their occupation as a consequence infection. ${ }^{12}$ Incapacity and arthralgia appear to increase with age but not to differ by sex. ${ }^{*}$

Despite the apparent differences in persistence of symptoms, patterns of functional recovery after the acute phase were remarkably similar between WA cases in 1988-89 and North Coast cases in 1992. In both studies, it was found that while most patients had resumed normal activities within six months, over 30 per cent were still unable to exercise or play sport at this time, over 20 per cent were unable to garden and 7 to 9 per cent were unable to walk unaided. ${ }^{12}$

Only 35 per cent of North Coast cases in 1992, but nearly 90 per cent of inland NSW cases in $1983-84,{ }^{4}$ were reported to have resumed their normal activities within three months. In this study, there were discrepancies between medical practitioner and patient estimates of periods of incapacity. It therefore seems likely that much of the apparent difference between North Coast and inland NSW cases may have been due to a relative underreporting of incapacity by medical practitioners, compared to patients.

The extent to which all of these estimates were biased by the lack of objective, particularly baseline, measurements, is uncertain. In particular, time off work and change of occupation among these patients may have been due, in whole or in part, to other factors. It is likely that some of the cases with persistent incapacity may have had other systemic or musculoskeletal conditions, for example osteoarthritis. However, there is other evidence that a proportion of those with Ross River virus infection do indeed progress to a chronic and incapacitating illness, compatible with a diagnosis of chronic fatigue syndrome. ${ }^{3}$ An epidemiological investigation of the syndrome on the North Coast in 1988, using extensive investigations to exclude alternative diagnoses, estimated a point prevalence of about 40 cases per $100000,{ }^{28}$ about 7 to 10 per cent of which appeared to follow laboratory-confirmed Ross River virus infection. ${ }^{3}$ 


\section{Prevention}

The increase in antibody prevalence with age on the North Coast ${ }^{8}$ is consistent with endemic sources of infection, Ross River virus being enzootic in most rural areas, with human outbreaks occurring when local conditions (rainfall, warm weather and hence vector breeding grounds) are favourable. Unfortunately, the North Coast presents ideal conditions for the breeding of mosquitoes, being characterised by many shallow lakes, swamps and river estuaries. ${ }^{8}$ Of particular concern is that many city people without immunity are moving to or visiting these mosquito-prone areas, the North Coast being the fastest growing area in NSW, and tourism being one of its major industries.

The mosquito vectors in coastal areas, Aedes vigilax and Aedes camptorhynchus, bite during the day. ${ }^{1}$ Probably the most important control measures are the use of mosquito repellents, the wearing of longsleeved shirts and trousers, the insect proofing of buildings and water tanks, and removal of domestic breeding sites. Effective planning should take into account vector breeding sites, particularly in view of predictions of increasing temperatures and flooding of low-lying areas as a consequence of the greenhouse effect. ${ }^{1}$

\section{Conclusions}

The clinical profile of Ross River virus patients on the North Coast of NSW is broadly consistent with previous reports from elsewhere in Australia. Some of the apparent discrepancies in patterns of symptoms and incapacity noted from previous reports are probably due to the inconsistent criteria and methods of measurement used in different investigations. In particular, it appears that medical practitioners may underestimate the more subjective symptoms (for example tiredness) and incapacity (for example time off work) relative to the self-reports of patients. Previous estimates of the direct economic costs, and indirect human costs, of Ross River virus infection based on data obtained from medical practitioners are almost certainly underestimates.

\section{Acknowledgments}

We would like to thank Dr Robert Condon of the Health Services Statistics and Epidemiology Branch, Health Department of WA, for providing advice and permitting the use (with minor modification) of the questionnaire developed to investigate the 1988-89 WA Ross River virus outbreak. We also gratefully acknowledge the contributions of the many medical practitioners and patients on the North Coast who responded to the questionnaires and therefore provided most of the information presented in this document. We also thank Geoff Sullivan and Joe Holloway, Environmental Health Officers at the North Coast Public Health Unit, for providing the initial impetus for the survey and their help during data collection.

\section{References}

1. Wolstenholme J. Ross River virus: an Australian export? [editorial ]. Med J Aust 1992; 156: 515-16.
2. Mudge PR, Aaskov JG. Epidemic polyarthritis in Australia, 1980-81. Med J Aust 1983; 2: 269-73.

3. Boughton CR, Hawkes RA, LIoyd A, Naim HN, et al. Post illness effects of Ross River virus infection [abstract]. Proceedings of the 5th Symposium on Arbovirus Research in Australia, Brisbane, 1989. Brisbane: CSIRO Division of Tropical Animal Production and Queensland Institute of Medical Research.

4. Hawkes RA, Boughton CR, Naim HM, Stallman ND, et al. A major outbreak of epidemic polyarthritis in New South Wales during the summer of 1983-1984. Med J Aust 1985; 143: $330-3$.

5. Clarke JA, Marshall ID, Gard G. Annually recurrent epidemic polyarthritis and Ross River virus activity in a coastal area of New South Wales. I. Occurrence of the disease. $A m J$ Trop Med Hyg 1973; 22: 543-50.

6. Marshall ID, Woodroofe GM, Gard GP. Arboviruses of coastal south-eastern Australia. Aust J Exp Biol Med Sci 1980; 58: 91-102.

7. Cloonan MJ, O'Neill BJ, Vale TG, Carter IW, et al. Ross River virus activity along the South Coast of New South Wales. Aust JExp Biol Med Sci 1982; 60: 701-6.

8. Boughton CR, Hawkes RA, Naim HM, Wild J, et al. Arbovirus infections in humans in New South Wales: Seroepidemiology of the alphavirus group of togaviruses. Med J Aust 1984; 141: 700-4.

9. Echuca-Melbourne Collaborative Group. Arbovirus infection in a Murray Valley Community. I. Prevalence of antibodies, December 1974. Med J Aust 1976; 1: 257-9.

10. NSW Health Department. Infectious disease notifications by Health Area and Region for January 1990-December 1990. NSW Public Health Bull 1991; 2: 15.

11. NSW Health Department. Infectious disease notifications by Health Area and Region cumulative 1992. NSW Public Health Bull 1993; 4: 7.

12. Condon RJ, Rouse IL. Acute symptoms and sequelae of Ross River virus infection in south-western Australia: a follow-up study. Clin Diag Virol 1994; 3: 273-89.

13. NSW infectious disease manual. Sydney: Epidemiology and Health Services Evaluation Branch, NSW Health Department, 1992.

14. Dean AG, Dean JA, Burton AH, Dicker RC. Epi Info Version 5. Atlanta, GA: Centers for Disease Control, 1990.

15. Australian Bureau of Statistics. Estimated resident populations by age and sex in statistical local areas, New South Wales, June 30 1992. Cat no. 3209.1. Canberra: ABS, 1994.

16. Report of monthly and yearly rainfall (Lismore-Centre Street) 1959-1992. Coffs Harbour: NSW Regional Office of the Bureau of Meteorology, Climate and Consultative Services, 1993.

17. Doherty RL, Barrett EJ, Gorman BM, Whitehead RH, et al Epidemic polyarthritis in eastern Australia 1959-70. Med Aust 1971; 1: 5-8.

18. Seglenieks Z, Moore BW. Epidemic polyarthritis in South Australia: report of an outbreak in 1971. Med J Aust 1974; 2 552-6.

19. Byrne B. Viral polyarthritis. Med J Aust 1984; 140: 445-6.

20. Anderson SG, Donnelley M, Stevenson WJ, Caldwell NJ, et al. Murray Valley encephalitis: surveys of human and anima sera. Med J Aust 1952; 1: 110-14

21. Wilson JG. The Murray Valley rash. Med J Aust 1957; 2 120-2.

22. Fraser JRE, Christie DG, Gust ID, White J, et al. Arbovirus infection in a Murray Valley community. Aust NZ J Med 1986; 16: 52-7

23. Mackenzie JS, Broom AK, Calisher $\mathrm{CH}$, Cloonan $\mathrm{MJ}$, et al. Diagnosis and reporting of arbovirus infections in Australia. Comm Dis Intell 1993; 17: 202-7.

24. Dowling PG. Epidemic polyarthritis. Med J Aust 1946; 1: 245-6.

25. Anderson SG, French EL. An epidemic exanthema associated with polyarthritis in the Murray Valley 1956. Med J Aust 1957; 2: 113 .

26. Halliday JH, Horan JP. An epidemic of polyarthritis in the Northern Territory. Med J Aust 1943; 2: 293-5.

27. Fraser JRE. Epidemic polyarthritis and Ross River virus disease. Clin Rheum Dis 1986; 12: 369-88.

28. Lloyd AR, Hickie I, Boughton CR, Spencer $O$, et al. Prevalence of chronic fatigue syndrome in an Australian population. Med J Aust 1990; 153: 522-8. 